\title{
Vibration Analysis of Narrow Tilting Three- Wheeled Vehicle Suspension System During Cornering
}

\author{
Maulana Syarif Habibi and Unggul Wasiwitono \\ Departemen Teknik Mesin, Fakultas Teknologi Industri \\ Institut Teknologi Sepuluh Nopember \\ e-mail: unggul@me.its.ac.id
}

\begin{abstract}
In Indonesia, there are a lot of vehicle on the road. These vehicles are used by the owner even there are only one or two passangers. That is the main reason of traffic jam in Indosia. However, motorbike is the best solution to fully use all part of the road that is provided in Indonesia because of its size, despite of motorbike has less safety than car. Therefore, combination between motorbike and car advantages have to be delivered through new type of vehicle which is narrow tilting threewheeled vehicle. The goal that we want to achive from this final project is to test the vibration which affected the Narrow Tilting Three-Wheeled Vehicle (NTTWV). The condition that we analize is when the Narrow Tilting Three-Wheeled Vehicle (NTTWV) oscilliating during cornering. This condition is important because in Indonesia, there are a lot of hole located on the cornering part of the road. This is important in order to make the vehicle comfortable to be use in any condition. To have a better analysis, we use three variation which are suspension angle, spring constant and length of the arm. From the research, we could conclude that in order to feel less vibration acceleration we have to decrease the spring constant. Another way to lessen the vibration impact, we could lowering the suspension angle. Lastly, we could extend the arm length in order to have lower vibration impact.
\end{abstract}

Keyword - NTTWV, Cornering, Vibration Acceleration.

\section{INTRODUCTION}

$\mathrm{T}$ HE traffic jam and also the parking area problems are caused by the increasing of car volume which make the society uncomfortable. Moreover, the pollution and its bad effect towards the environment also the problem caused by the vehicle volume. These conditions lead to the innovations in creating vehicle such as smart vehicle, narrow vehicle and also green vehicle. Recently, a lot of electrical vehicle which has a better efficiency and also new driver system is created by manufacturers. In addition, in order to minimize the space that is occupied by each vehicle, a narrow vehicle would be the best solution and could be the alternative for future transportation system.

In the recent decades, there are several researches on narrow vehicle. The problem in developing the narrow vehicle for future solution is on how we are going to develop this type of vehicle that is safe, stable and easy to maneuver. The alternative solution for this problem is by creating the vehicle that has the ability to lean or tilt its body like motor bike. To allow this kind of movement, the vehicle has to have a complex suspension system compare to the motor bike or car suspension system.

Suspension is one of the most important part of a vehicle. Suspension has the function for connecting the body and its tire and also to make sure that the tire always has a contact with the road. The performance of the suspension has to be evaluated with three criteria. First is the comfort, which is how well the suspension isolating the vibration caused by the random surface of a road. The second, is the safety, which is the ability to maintain contact with the road (road holding). And last is the deflection of the suspension has to be smaller that its limit. Those three conditions actually can not be achieved equally where we have to compromise between those three performances. Lately, the researches that have been conducted are talking about reducing clash between the comfort and suspension ability to keep the tire stick to the road at the same time.

In analyzing the vehcile movement, we realize that every single part of the vehicle is matter. If a part is changed then it will affect the vehicle in every aspects. A research conducted by Rizal P. Restuaji found that With the linkage geometry variations, it will bring an effect toward its turning angle. This also affect the stability of the vehicle where the vehicle will have an ackerman condition if the appropriate length of arm is applied[1]. Another research which learning about the narrow tilting vehicle is the one that conduceted by Maulana Fajar Nur Hidayat. He was trying to figure out about narrow tilting three-wheeled vehicle vibration response through a speed bump. Then he found with lower spring constant, the user will be more comfortable[2]. Although those research had been conducted, we are going to find out the vibration of the narrow tilting three-wheeled vehicle during cornering with several variations.

Narrow tilting vehicle is a combination of car's comfort and motorbike's dynamic where the vehicle could tilt while cornering to counter force that cause the vehicle to roll. If this vehicle not tilting during cornering, the vehicle will roll over[3].Therefore, this vehicle have a different configuration or different suspension system in order to have the dynamic as a motorbike. There are 3 patents that can be used in designing the narrow tilting three-wheeled vehicle. First is the configuration discovered by Edward M. Smith and Robert E. Mciver with patent number US8070172 B1[4]. Next is the configuration discovered by Suhre, R.J. et al with patent number US7591337 B2[5]. However, in this research we use the configuration invented by Daniel Mercier with patent number US 8762003 B2[6]. This configuration will maintain the value of spring constant even when the vehicle is tilted.

The research is focusing on simulation where modelling of the vehicle is the important part. In this research, the usage of multibody modelling will be the appropriate one where full analysis of the forces could be done. This is important as if a vehicle in cornering condition, there will be several forces working on it. Generally, two main forces that have big effect toward the sability of the vehicle are the friction force and the 
lateral force or centrifugal force. If there is an imbalance condition of these force, the vehicle will roll over[7]. The forces that work on a vehicle during cornering is shown on Figure 1.

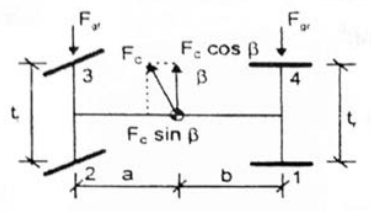

(a)

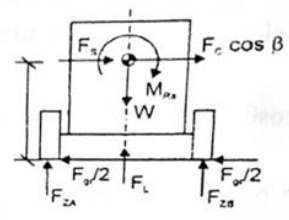

(b)

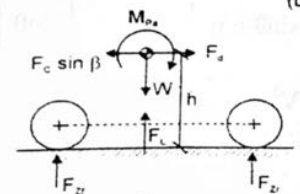

(c)
Figure 1. Forces During Cornering [7]

In accordance with the analysis, the vibration analysis can be done with several method that existed. The most common method that is used is using statistical measurement from the vibration signal. Root-mean-square has become the most common one in analyse the vibration. Its basically only finding the standard deviation of the vibration signal[8].

The objective from this research is to study the effect of linkage geometry and spring constant toward kinematic and dynamic suspension system of the Narrow Tilting ThreeWheeled vehicle during cornering and also analyzing the vibration response of Narrow Tilting Three-Wheeled vehicle.

\section{METHODOLOGY}

In conducting the research, there are several steps that have to be done. At the beginning the research, we are finding the information through literature review. Then followed by determining vehicle geometry. After that create the model in Inventor 2018 where we could simulate the model afterward. And last is analysis of the result with root-mean-square method.

\section{A. Flowchart}

In executing the research, there are several structural steps to ensure the research flow that is taken and will deliver a maximum result. The work flow is presented by the flowchart of narrow tilting vehicle design and simulation for this final project as shown at Figure 2 to ease the reader in understanding how the flow of the final project or this research.

\section{B. Narrow Tilting Three-Wheeled Vehicle Geometry}

We create the model as a size of a motor bike but with 2 wheel in front with a width about human body while sitting. For the human model, we find the reference from internet to figure out the human size. For the engine we imitate the engine of a motor bike and put it at the back. All the sizing are actually based on motor bike size and also human body size.

\section{Narrow Tilting Three-Wheeled Vehicle Modelling}

After all the size is determined, then we create the model in Inventor 2018. In this stage we have to create each part like the tire, steering, chasis and other parts. After that we have to assembly them into one unit of vehicle model. Next, we can set some setting of the simulation such as the spring, joint, and other moving relation in the model. Then the model can be simulated. The model for the simulation can be seen on Figure 3.

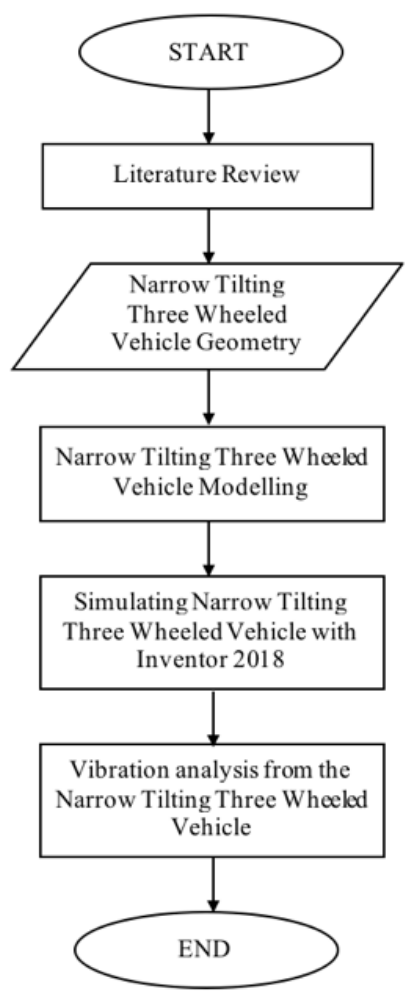

Figure 2. Flowchart of the Research

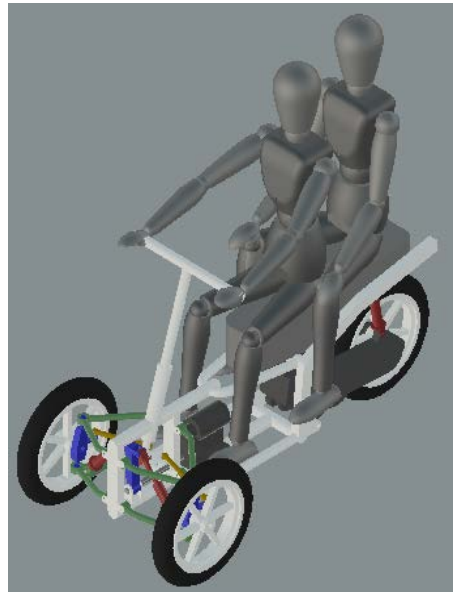

Figure 3. Simulation Modelling

\section{Simulating Narrow Tilting Three-Wheeled Vehicle with Inventor 2018}

The simulation will be done several time with all the variations which are the spring constant, arm length and the suspesion angle. All the properties and the condition have to be maintain at the same position to make it appropriate to be compared. The most important thing is plotting the tracer to analyze movement on the model. we put the tracer at the driver's body. As the result, we will get the graph of acceleration on vertical direction as the vibration which affect the passanger and the driver.

The utilization of inventor as the software for simulation is important because it is going to be complex thing if we analyze it manually using dynamic system and its mathematical model. It is complex because there are a lot of forces affecting the vehicle.

On the the vehicle, there are normal forces $F_{N}$, excitation force $F_{e k s}$, projected cetrifugal forces $F_{y}$ and $F_{x}$, weight of 
the vehicle $F_{w}$, friction $F_{f}$, and also the moment of rolling and pitching. Excitation force is the force that generated because of the impact from the tire toward the hole on the road. Normal forces is the force from contact between the tire and the road. Friction is hte force generated because of the cornering movement where this force will counter the lateral forces. The rolling moment will only affect the vehicle if the lateral force can counter all the forces which will make the vehicle roll or we can say when the tire is lifted. And for the pitching moment will affect when the vehicle passing through an obstacle.

This vehicle has a different mechanism which allow the vehicle to tilt. The tilting condition will make the position of the CG (center of gravity is moving. The condition makes the vehicle different from car but similar with motor bike. When the CG position is changing then the moment from all the forces will also be change. The distance between CG and the forces is changing along with its tilting position. Other thing that should be noticed that the rolling phenomenon because of the rolling moment and also the sliding phenomenon. These phenomenon will impact the stability of the vehicle.

\section{RESULT AND DISCUSSION}

\section{A. Vehicle Model and Simulation Specifications}

To undestand the simulation, specification of the vehicle will be explained. This vehicle is powered with an engine on its back which is designed with front wheel steering. The specification is represeneted on the Table 1 . And for the detail of the model, it can be seen on the Figure 4 which show the vehicle and its track with the hole as the obstacle. The details are identified from the model properties in Autodesk Inventor 2018 simulation.

Table 1.

Narrow Tilting Three-Wheeled Vehicle Parameter

\begin{tabular}{lll}
\hline \multicolumn{1}{c}{ Parameter } & Value & Measurement \\
\hline Total Mass & 233 & $\mathrm{Kg}$ \\
Sprung Massa & 167 & $\mathrm{Kg}$ \\
Track width & 0.645 & $\mathrm{~m}$ \\
Whell base & 1.3 & $\mathrm{~m}$ \\
Tire Diameter & 0.43 & $\mathrm{~m}$ \\
Front Arm Length & 0.25 & $\mathrm{~m}$ \\
Tire stiffness Constant Toward the Road & 1000 & $\mathrm{~N} / \mathrm{mm}$ \\
Damping Constant of the Tire Toward & 1 & $\mathrm{~N} . \mathrm{s} / \mathrm{mm}$ \\
the Road & & \\
Friction Coefficient of the Tire & 0.9 & - \\
\hline \hline
\end{tabular}

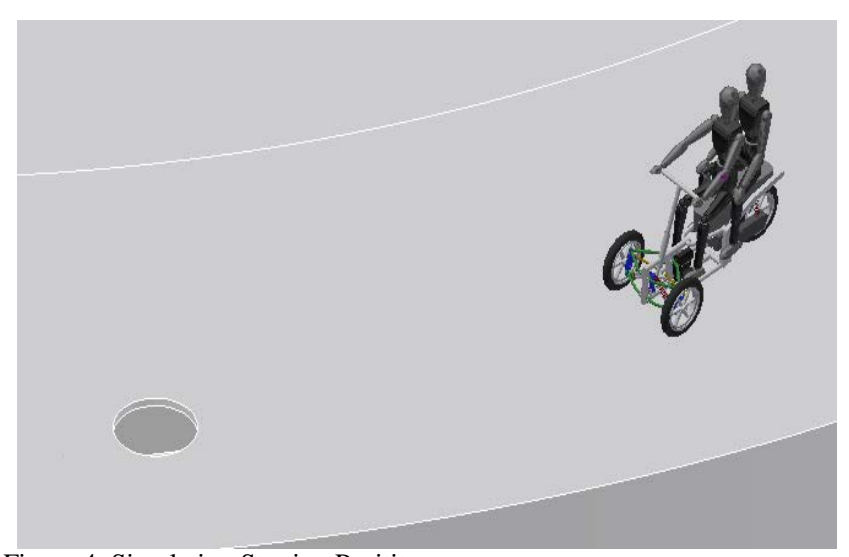

Figure 4. Simulation Starting Posititon
In the simulation, the model of the simulation will move with steering angel about $7^{\circ}$ with the tilting angle about $7^{\circ}$. The vehicle will move with constant velocity about $19.8 \mathrm{~km}$ per hour. For the input, we will use a hole with the diameter of the hole $750 \mathrm{~mm}$ and depth about $70 \mathrm{~mm}$. The location of the hole is in front of the vehicle starting position where the vehicle will get pass through it at $9 \mathrm{~s}$ of the simulation. The simulation will only take about $12.5 \mathrm{~s}$.

\section{B. Data analysis}

In this research, we have the data from the simulation that is executed with help from a software which is inventor. We simulate the model and then the software will provide you a graph as the output where we put a tracer first at the user body. This graph shows the vibration that happen at the user through a certain time. We can see the graph on figure 5 .

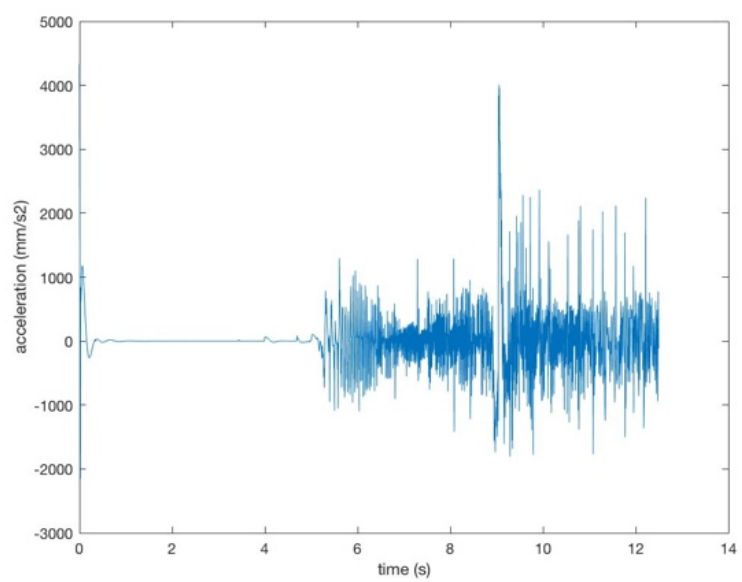

Figure 5. Vibration Result from the Autodesk Inventor Dynamic Simulation

From the graph that we have from the software, we can see that at the beginning of the simulation, the vehicle is vibrating. This is the section where the vehicle is firstly affected by the gravity and touch the ground. After that, there is no vibration happen which in this section, the vehicle is stabilizing its position to be straight perpendiculat towards the ground. And then on the graph we could see the vibration is happening again when the vehicle starts to move and cornering at $5 \mathrm{~s}$ of the simulation. Around $9 \mathrm{~s}$ of the simulation, we could see the graph is reaching its peak because the vehicle is passing the hole. We know that the graph really show how vibration happen on the vehicle. However, the graph shows some noise which lowering the accuracy of the data. That is why we are going to use data filtering. The filtering process is using matlab lowpass filter to eliminate the noise. Through the programme, we could deliver new graph with better accuracy because the noise has been eliminated. The graph is shown at Figure 6.

After filtering the data, then the data is ready to be used. We are going to calculate the root-mean-square (RMS) of the vibration with the filtered data. We calculate the root-meansquare (RMS) by first squaring each data. After that we find the mean of the data population. Then rooting the mean from the process. We calculate the root-mean-square (RMS) from all the simulation result. Lastly we plot it into a graph in order to see the trenline of it. This is important to understand the average acceleration for the vibration on the vehicle. 


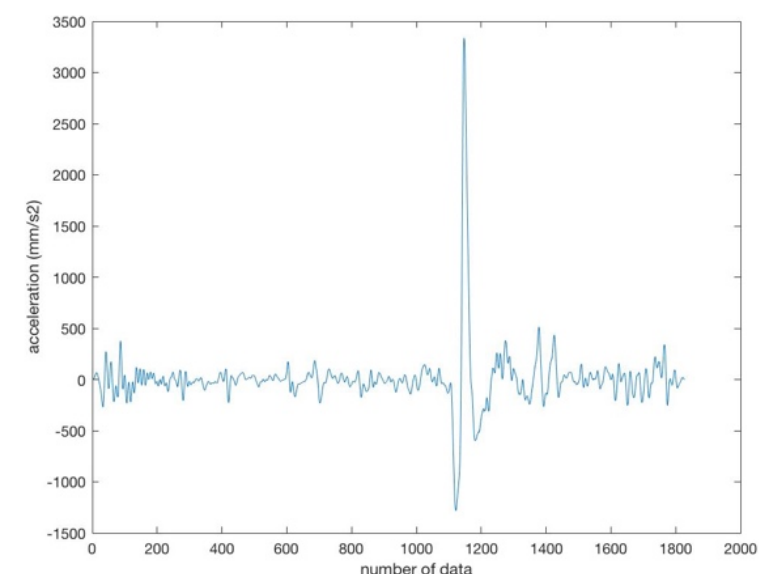

Figure 6. Filtering Process with MATLAB

\section{Response Affected by Spring Constant Variation}

In suspension, there are several components that assembled into one form of suspension. One of the important component is the spring. Spring have a big role in suspension which absorbing the energy that affect them. The suspension is working with damper in order to absorb and eliminate the energy taken because of the random road profile. This condition has to be analysed where the variations of the spring constant will affect the vibration response of a vehicle. In this part of the research, we use $250 \mathrm{~mm}$ as its arm length and the suspension angle is about $45^{\circ}$. However, for the spring constant that is used, the variation is around $50 \mathrm{~N} / \mathrm{mm}$ - $150 \mathrm{~N} / \mathrm{mm}$ with about $25 \mathrm{~N} / \mathrm{mm}$ difference on each simulation. After we set all the modelling properties and position. Then the simulation is executed. And from the simulation we can see the vibration that affect the user from the graph that is provided from the software. From the graph, the data is accumulated and processed with Root Mean Square method. And then plot it into one graph as shown on Figure 7.

As shown on the graph, the trenline of the graph is inclining which is showing the variations of the spring constant will affect the vibration response. From the graph, the lowest acceleration is about $0.3158647309 \mathrm{~m} / \mathrm{s}^{2}$ when the spring constant is $50 \mathrm{~N} / \mathrm{mm}$. And the highest acceleration is about $0.4337554246 \mathrm{~m} / \mathrm{s}^{2}$ when the spring constant is 125 $\mathrm{N} / \mathrm{mm}$. We can conclude that if the spring constant is lower, it is better in minimizing the vibration on the vehicle as we can see from the graph. This phenomenon is appropriate. According to the theory, as the spring constant increase, the forces that impact the vehicle will be higher. This condition will make the user not comfortable.

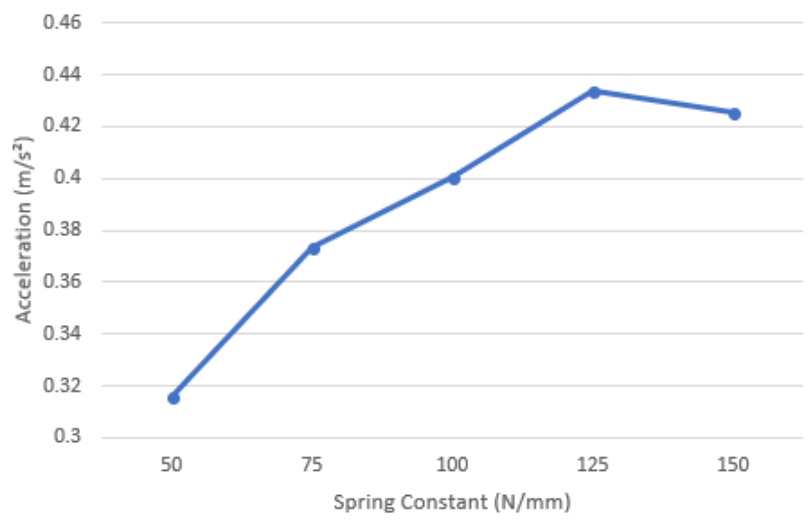

Figure 7. Root-Mean-Square of the Vibration related with Spring Constant Variation

\section{Vibration Response Affected by Suspension Angle Variations}

In using the suspension on a vehicle, we usually put it with a certain position and angle. This condition actually affects the performance of the suspension in absorbing the energy and prevent it from excited. To understand the effect of the variations, we have to do a simulation. In this part of the research, we use $250 \mathrm{~mm}$ as its arm length and the spring constant is about $50 \mathrm{~N} / \mathrm{mm}$. However, for the suspension angle that is used, the variation is around 35 - 45 with about 2,5 difference on each simulation. After we set all the modelling properties and position. Then the simulation is executed. And from the simulation we can see the vibration that affect the user from the graph that is provided from the software. From the graph, the data is accumulated and processed with Root Mean Square method. And then plot it into one graph as shown on Figure 8.

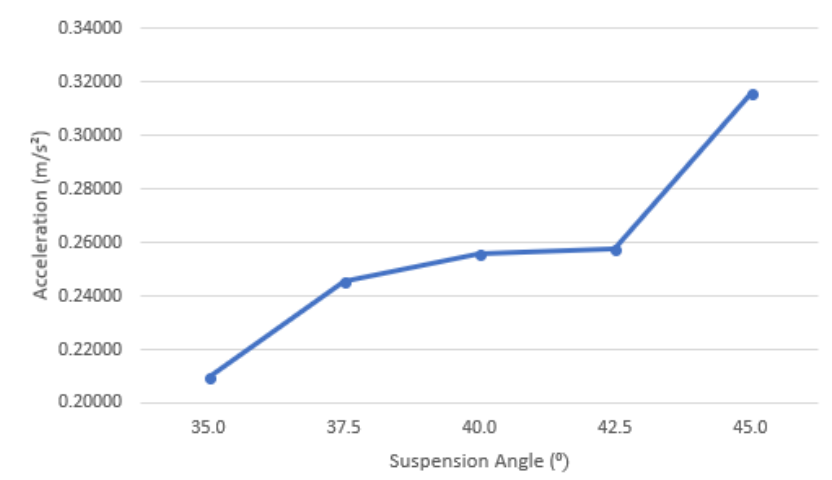

Figure 8. Root-Mean-Square of the Vibration related with Suspension Angle Variation

Variation As shown on the graph, the trenline of the graph is inclining which is showing the variations of the spring constant will affect the vibration response. From the graph, the lowest acceleration is about $0.209680711 \mathrm{~m} / \mathrm{s}^{2}$ when the spring constant is $35^{\circ}$. And the highest acceleration is about $0.3158647309 \mathrm{~m} / \mathrm{s}^{2}$ when the spring constant is $45^{\circ}$. We can conclude that if the suspension angle is low, it is better in minimizing the vibration on the vehicle. The graph has shown an inclination of its trenline which is appropriate with the theory. If we put the suspension with certain angle then the forces of the suspension have to be projected with sin function. From that theory, as the angle increase, the sin will also increase.

\section{E. Vibration Response Affected by Arm Length Variations}

In order to maintain the sability of a vehicle, the length of an arm could be one of the variation that affect its stability. Although the stability of a car may have an impact to the comfort of the user. Therefore in a simulation have to be done to understand the effect of arm length variations toward the vibration in a vehicle. In this part of the research, we use 50 $\mathrm{N} / \mathrm{mm}$ as its spring constant and the suspension angle is abour $45^{\circ}$. However, for the arm length that is used, the variation is around $250 \mathrm{~mm}$ - $350 \mathrm{~mm}$ with about $50 \mathrm{~mm}$ difference on each simulation. After we set all the modelling properties and position. Then the simulation is executed. And from the simulation we can see the vibration that affect the user from the graph that is provided from the software. From the graph, the data is accumulated and processed with Root Mean Square method. And then plot it into one graph ash shown on Figure 9. 


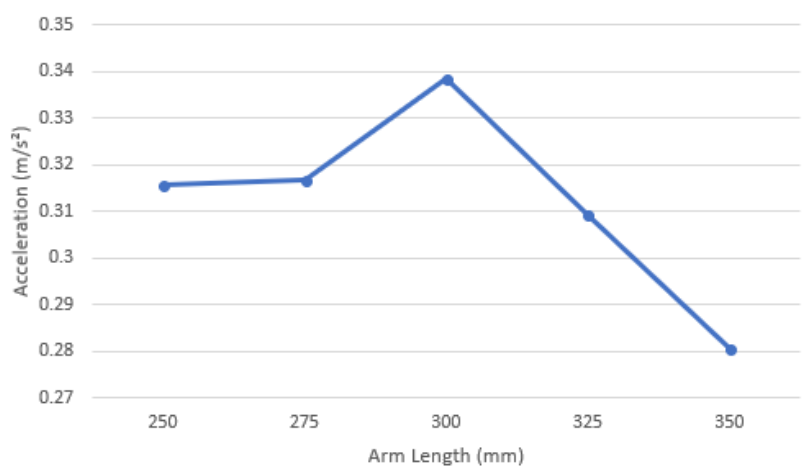

Figure 9. Root-Mean-Square of the Vibration related with Arm Length Variation

As shown on the graph, the trenline of the graph is declining which is showing the variations of the spring constant will affect the vibration response. From the graph, the lowest acceleration is about $0.280557314 \mathrm{~m} / \mathrm{s}^{2}$ when the arm length is $350 \mathrm{~mm}$. And the highest acceleration is about $0.338510052 \mathrm{~m} / \mathrm{s}^{2}$ when the arm length is $300 \mathrm{~mm}$. We can conclude that the extending the arm length, it will minimizing the vibration on the vehicle. Based on the theory, torsion is a result of a force that working towards a certain point times the distance to the point. From that we know actually as the arm is longer, the torsion affect the vehicle will be higher. But on the trenline from the simulation show different conclusion. This phenomenon can be caused by several reasons such as a miss from the program or maybe there is other force affect on the vehicle as the displacement of the suspension.

\section{CONCLUSION}

Throughout the final project research, we have two conclusions from the analysis of suspension geometry that affect the vibration towards the narrow tilting vehicle. First, we have understand that the changes of linkage geometry and spring constant could affect the kinematic and dynamic suspension system of NTTWV during cornering. The second one is the vibration response of NTTWV during cornering is varied depend on the linkage geometry and spring constant. The result show, with spring constant variation, the lowest acceleration is when the spring constant is $50 \mathrm{~N} / \mathrm{mm}$ and the highest acceleration is when the spring constant is $125 \mathrm{~N} / \mathrm{mm}$ where the trenline is inclining. With suspension angle variation, the lowest acceleration is when the spring constant is $35^{\circ}$ and the highest acceleration is when the spring constant is $45^{\circ}$ where the trenline is inclining. With arm length variation, the lowest acceleration is when the arm length is $350 \mathrm{~mm}$ and the highest acceleration is when the arm length is $300 \mathrm{~mm}$ where the trenline is declining. Therefore, the best suspension in eliminating the vibration is the one with low spring constant, low suspension angle and shorter arm length.

\section{REFERENCES}

[1] R. P. Restuaji and U. Wasiwitono, "Perancangan dan analisa sistem kemudi dan sistem suspensi quadrilateral pada narrow tilting vehicle,” J. Tek. ITS, vol. 5, no. 2, pp. E122-E127, Dec. 2016.

[2] M. F. N. Hidayat, "Analisa dinamis pengaruh variable geometry suspension pada narrow tilting vehicle,” Institut Teknologi Sepuluh Nopember, 2017.

[3] A. Zandieh, "Dynamics of a three-wheel vehicle with tadpole design," University of Waterloo, 2015.

[4] E. M. Smith and R. E. McIver, "Leaning vehicle suspension," US8070172B1, 12-Feb-2010.

[5] R. J. Suhre, A. D. Massignan, A. H. Roth, M. Hutchison, and S. J. Saiki, "Leaning suspension mechanics," US7591337B2, 27-Sep2006.

[6] D. Mercier, "Leaning vehicle with tilting front wheels and suspension therefor,” US20120232758A1, 16-Nov-2009.

[7] I. N. Sutantra, Teknologi Otomotif Hybrid, 1st ed. Surabaya: Guna Widya, 2010.

[8] N. J. Mansfield, Human response to vibration. New York: CRC Press, 2005. 